Tropical Journal of Pharmaceutical Research February 2013; 12 (1): 45-49

ISSN: 1596-5996 (print); 1596-9827 (electronic)

(C) Pharmacotherapy Group, Faculty of Pharmacy, University of Benin, Benin City, 300001 Nigeria.

All rights reserved.

Available online at http://www.tjpr.org

Original Research Article

http://dx.doi.org/10.4314/tjpr.v12i1.8

\title{
Sodium Carboxymethyl Chitosan as a Fixative for Eau de Cologne
}

\author{
Surawut Wannaruemon ${ }^{1,2}$ Ampa Jimtaisong ${ }^{1^{*}}$ and Pornchai Rachtananpun ${ }^{3,4}$ \\ ${ }^{1}$ School of Cosmetic Science, Mae Fah Luang University, 333 Moo1, Thasud, Muang, Chiang Rai, 57100, ${ }^{2}$ Bangkok Perfumery, \\ Co., Ltd., Muang, Nonthaburi 11000, ${ }^{3}$ Division of Packaging Technology, Faculty of Agro-Industry, Chiang Mai University, \\ Muang, Chiang Mai 50100, ${ }^{4}$ Materials Science Research Center, Faculty of Science, Chiang Mai University 50200, Thailand
}

*For correspondence: E-mail: ampa@mfu.ac.th; Tel:+6653916843; Fax: +6653916831

Received: 28 March 2012

Revised accepted: 12 December 2012

\begin{abstract}
Purpose: To study the characteristics of sodium carboxymethyl chitosan (SCM-chitosan) as a fixative for eau de cologne product.

Methods: SCM-chitosan was prepared by carboxymethylation reaction of chitosan with monochloroacetic acid. The solubility of SCM-chitosan was investigated in water and ethanol. Sixteen perfume compounds which consisted of four chemical types - alcohols, ketones, aldehydes and ethers - were selected for eau de cologne preparation. The turbidity of the products prepared was monitored over 21-day aging period. Those showing no turbidity were selected for fixative studies with SCM-chitosan. The fixative effect of SCM-chitosan was evaluated by head space gas chromatography at different temperatures $\left(25,35\right.$ and $\left.53^{\circ} \mathrm{C}\right)$.

Results: The prepared SCM-chitosan was soluble in water but insoluble in ethanol. The optimum ratio between water and ethanol that could completely dissolve $0.1 \%$ SCM-chitosan was 2:3 v/v. SCM-chitosan showed significant fixative effect (3.9 - 92.2\%) on p-cresyl methyl ether (10\% in dipropyleneglycol). Fixative efficiency increased from $3.9 \%$ at $25^{\circ} \mathrm{C}$ to $42.1 \%$ at $35^{\circ} \mathrm{C}$ and $92.2 \%$ at $53^{\circ} \mathrm{C}$. However, products containing benzyl alcohol, ethyl acetoacetate and 94085 floral-fruity showed precipitation after 21 days.

Conclusion: The results obtained indicate that SCM-chitosan could be used as a potential fixative for eau de cologne products.

Keywords: Biopolymer, carboxymethyl chitosan, cologne, fixative, perfume

Tropical Journal of Pharmaceutical Research is indexed by Science Citation Index (SciSearch), Scopus, International Pharmaceutical Abstract, Chemical Abstracts, Embase, Index Copernicus, EBSCO, African Index Medicus, JournalSeek, Journal Citation Reports/Science Edition, Directory of Open Access Journals (DOAJ), African Journal Online, Bioline International, Open-J-Gate and Pharmacy Abstracts
\end{abstract}

\section{INTRODUCTION}

Eau de cologne is a product consisting of low quantity of perfume compounds but high volume of alcohol and water. The products are generally available as a refreshing body splash. Poor tenacity is an important weakness of cologne products; however, it is compensated with attractive refreshing scent and low price [1]. From a practical point of view, long tenacity means a gradual release or constantly volatile activity over a long period of time. Hence, many substances are used as perfume sustainedrelease agents and fixative, e.g., co-polymers [2], cyclodextrins [3] and microcapsules [4].
The mechanism of sustaining perfume release is still not clearly understood. It likely involves hydrogen bonding of fixative agent and perfume compound, a process known as fixation [5]. The ability of poly(ethyleneoxide)/poly(propyleneoxide)/poly(ethyleneoxide) copolymers to decrease the volatilization of eu de cologne products have been reported. It was investigated by means of dynamic and static headspace analysis [2]. Suppression of the volatility of perfume compounds by EO/PO/EO copolymer was markedly greater than by polyethylene glycol. This suppressive effect may be due to micelle and gel formation of EO/PO/EO copolymer. This triblock copolymer is expected 
to be useful as a novel sustained-release carrier. However, it still has a weak point due to gel formation as a result of rise in temperature [2].

Chitosan is a polymer of glucosamine, obtained as a deacetylated product of chitin, which is a byproduct of squid, crab and shrimp processing. The degree of deacetylation and molecular weight of chitosan determine its physical and chemical properties. Chitosan has been reported to have many desirable properties such as nontoxicity, biodegradability, biocompatibility, and anti-microbial characteristics. Moreover, its ability to encapsulate volatile citronella oil and controlled-release effect is of great interest [6]. However, the potential application of chitosan is hindered by its limited solubility in aqueous media due to the presence of abundant hydrogen bonds and its semi-crystalline properties [7]. Thus, chitosan is chemically modified so as to improve the polymer processability, solubility, antimicrobial activity and the ability to interact with other substances [8]. Chitosan possesses a high amount of hydroxyl groups closely similar to those of triblock copolymer and cyclodextrin, which are able to decrease volatility of perfumes. Therefore, it is of interest to study if it can be used as perfume fixative in a high alcohol and water content eau de cologne product. Shrimp chitosan, which is regarded as waste in food industry and therefore inexpensive, was used as the fragrance fixative. Thus, this work attempts to prepare a water soluble chitosan derivative and investigate its potential use as a fixative agent in eau de cologne products.

\section{EXPERIMENTAL}

\section{Materials}

Shrimp chitosan with a degree of deacetylation > $85 \%$ and molecular weight of $10^{6}-1.5 \times 10^{6}$ Dalton, was purchased from Ta Ming Enterprises Co, Ltd., Thailand. It was milled by an electric grinder (Philips HL1632, Philips Electronics) to obtain the powder. Monochloroacetic acid, sodium hydroxide (industrial grade), isopropanol, ethanol (cosmetic grade), aroma materials (phenethyl alcohol, benzyl alcohol, linalool, geraniol, $\alpha$-ionone, $\beta$-ionone, $\alpha$-methyl ionone, citral, hydroxy citronellal, $p$-cresyl methyl ether (10 \% in dipropylene glycol), diethyl malonate, ethyl benzoate, ethyl acetoaetate, phenyl ethyl acetate, benzyl acetate and 94085 floral-fruity) and distilled water were supplied by Bangkok Perfumery, Thailand, and used without further purification.
Preparation of sodium carboxymethyl chitosan (SCM-chitosan)

Sodium carboxymethyl chitosan was prepared according to the method of Liu et al [9]. Chitosan $(10 \mathrm{~g})$, sodium hydroxide $(13.5 \mathrm{~g})$, water $(20 \mathrm{ml})$ and isopropanol $(80 \mathrm{ml})$ were added into a 500 $\mathrm{ml}$ flask to swell and then to alkalize at $50{ }^{\circ} \mathrm{C}$ for $1 \mathrm{~h}$. It was maintained at this temperature in a water bath. Monochloroacetic acid (15 g) was dissolved in isopropanol $(20 \mathrm{ml})$, and added to the reaction mixture dropwise over $30 \mathrm{~min}$, allowed to react for $4 \mathrm{~h}$ at the same temperature, and then the reaction was stopped by adding 70 $\%$ ethanol $(200 \mathrm{ml})$. The solid was filtered and rinsed in $70 \%$ ethanol to de-salt and de-water, and then dried at room temperature. Mass ratio (\%) was calculated from the ratio of the mass of SCM-chitosan and chitosan used.

\section{Preparation of eau de cologne}

Eau de cologne was prepared by mixing $3 \%$ of perfume compound with water and ethanol at optimal ratio. SCM-chitosan was dissolved in water phase; microwave irradiation (mediumhigh, $2 \mathrm{~min}$ ) was used to facilitate the solubility. Perfume compound was diluted with ethyl alcohol (95\%) and then slowly poured into the aqueous phase. In order to assess the physical appearance of the prepared product, the turbidity of the preparation was visually observed over period of 21 days.

\section{Evaluation of fixative effect}

Static headspace analysis technique using a gas chromatographic apparatus (Agilent 7890A GC System, Agilent Technologies) was used to evaluate the volatility of the products. Eau de cologne containing $0.5 \mathrm{ml}$ of each perfume compound, i.e., benzyl alcohol, ethyl acetoacetate, p-cresyl methyl ether and 94085 floral-fruity, with and without SCM-chitosan, were placed in a sample vial $(1.5 \mathrm{ml})$ and sealed with a silicon septum. Each vial was allowed to equilibrate for $30 \mathrm{~min}$ in a water bath at 25, 35 and $53{ }^{\circ} \mathrm{C}$ before injection into the gas chromatograph. Approximately $500 \mu \mathrm{l}$ of vapor of perfume compound above the solution was drawn out from the vial with the gas-tight syringe. The sample volume was adjusted to $300 \mu \mathrm{l}$, and then injected into the gas chromatograph in splitless mode. Helium was used as the purge gas. The column temperature was increased at the rate of $10^{\circ} \mathrm{C} / \mathrm{min}$ from a starting temperature of $80^{\circ} \mathrm{C}$ to $180^{\circ} \mathrm{C}$. The gas chromatograph was equipped with a DB-5 column, $60 \mathrm{~m}$ length, 0.25 $\mathrm{mm}$ inner diameter and $1.0 \mu \mathrm{m}$ film thickness and flame ionization detector (FID) heated at 300 
${ }^{\circ} \mathrm{C}$. The oven temperature was programmed from $80\left(1 \mathrm{~min}\right.$ hold) to $180^{\circ} \mathrm{C}$ at a rate of $10^{\circ} \mathrm{C} / \mathrm{min}$ and final hold at $220^{\circ} \mathrm{C}$ for $3 \mathrm{~min}$.

The fixative efficiency $\left(\% F X_{\text {eff }}\right)$ of SCM-chitosan on different perfume compounds was calculated from $\mathrm{Eq} 1$.

$\% F X_{\text {eff }}=\left[\frac{\text { Area }_{\text {ctrl }}-\text { Area }_{\text {scmt }}}{\text { Area }_{\text {ctrl }}}\right] \times 100$

where fixative efficiency (\%) compared with control, Area ${ }_{\text {ctrl, }}$ is the peak area of controlled sample and $A r e a_{\text {scmt }}$ is peak area of the product containing SCM-chitosan.

\section{Statistical analysis}

The experiments were performed in triplicate and the volatility values calculated and presented as mean. The deviation from the mean at the $95 \%$ significance level was used to determine differences in the data.

\section{RESULTS}

\section{Yield and solubility of SCM-chitosan}

Swelling and alkalinizing of shrimp chitosan resulted in the production of a translucent material which later became opaque after carboxymethylation step. The SCM-chitosan obtained was a white powder with weak basicity $(\mathrm{pH} 8)$. The mean $\%$ mass ratio obtained was 374.45. The number is higher than 100 because it is calculated by comparing the raw SCMchitosan obtained with the starting chitosan used in the preparation.
SCM-chitosan at concentrations of $0.01-0.2 \%$ was used to determine its maximum solubility in the preparation and it was found to be $0.1 \%$. SCM-chitosan was insoluble in ethanol which is a major component $(60-90 \%)$ in eau de cologne. Hence, the optimal quantity of water content was investigated and the optimum water/ethanol ratio for complete dissolution of 0.1 $\%$ SCM-chitosan was 2:3 v/v. The results of turbidity test of eau de cologne containing $0.1 \%$ SCM-chitosan are shown in Table 1.

Benzyl alcohol, ethyl acetoacetate, p-cresyl methyl ether and 94085 floral-fruity remained transparent and so they were selected for evaluating fixative effect.

\section{Fixative effect}

Fixation will occur when SCM-chitosan is soluble and consistent in the system. Volatile content calculated from the sum of peak areas of the chromatograms is shown in Table 2. Products containing SCM-chitosan $\left(\mathrm{BAL}_{\text {scmt }}, \mathrm{EAA}_{\text {scmt }}\right.$, $\mathrm{PCME}_{\text {scmt }}$ and $\mathrm{Sex} \mathrm{G}_{\mathrm{scmt}}$ ) showed lower volatile content than control $\left(\mathrm{BAL}_{\text {ctrl }}, \mathrm{EAA}_{\text {ctrl }}, \mathrm{PCME}_{\text {ctrl }}\right.$ and $\left.\operatorname{Sex} G_{\text {ctr }}\right)$. Three products showed varied results, namely, ethyl acetoacetate (EAA) at 53 ${ }^{\circ} \mathrm{C}$, and 94085 floral-fruity (SexG) at $35^{\circ} \mathrm{C}$ and $53{ }^{\circ} \mathrm{C}$. The remarkably low concentration of various active perfume compounds in 94085 floral-fruity which is a mixture of unknown chemical types might have been responsible for this behaviour.

The calculated results for fixative efficiency $\left(\% \mathrm{FX}_{\text {eff }}\right)$ of SCM-chitosan in different perfume compounds are shown in Table 3.

Table 1: Turbidity of eau de cologne products containing $0.1 \%$ SCM-chitosan

\begin{tabular}{|c|c|c|c|c|}
\hline \multirow{2}{*}{$\begin{array}{l}\text { Functional } \\
\text { group }\end{array}$} & \multirow[t]{2}{*}{ Perfume compound } & \multicolumn{3}{|c|}{ Turbidity* } \\
\hline & & Day 1 & Day 2 & Day 21 \\
\hline \multirow[t]{4}{*}{ Alcohol } & Phenethyl alcohol & + & + & + \\
\hline & Benzyl alcohol & - & - & - \\
\hline & Linalool & + & + & + \\
\hline & Geraniol & + & + & + \\
\hline \multirow[t]{3}{*}{ Ketone } & $\alpha$-lonone & + & + & + \\
\hline & $\beta$-Ionone & + & + & + \\
\hline & a-Methyl ionone & + & + & + \\
\hline \multirow[t]{5}{*}{ Ester } & Diethyl malonate & Precipitate & Precipitate & Precipitate \\
\hline & Ethyl benzoate & + & + & + \\
\hline & Ethyl acetoacetate ${ }^{* *}$ & - & - & - \\
\hline & Phenyl ethylacetate & + & + & + \\
\hline & Benzyl acetate & - & + & + \\
\hline \multirow[t]{2}{*}{ Aldehyde } & Citral & + & + & + \\
\hline & Hydroxycitronellal & + & + & + \\
\hline Ether & $p$-Cresyl methyl ether & - & - & - \\
\hline Mixture & 94085 Floral-fruity & - & - & - \\
\hline
\end{tabular}


Table 2: Volatility of perfume compounds in eau de cologne calculated from area peak at different temperatures.

\begin{tabular}{lllcl}
\hline Perfume compound & Sample code & \multicolumn{3}{c}{ Area peak } \\
\cline { 3 - 5 } & & $\mathbf{2 5}^{\circ} \mathbf{C}$ & $\mathbf{3 5 ^ { \circ } \mathbf { C }}$ & $\mathbf{5 3}^{\circ} \mathbf{C}$ \\
\hline Benzyl alcohol & $\mathrm{BAL}_{\text {ctrl }}$ & $3.81 \times 10^{5}$ & $3.16 \times 10^{5}$ & $3.49 \times 10^{4}$ \\
& $\mathrm{BAL}_{\text {scmt }}$ & $2.87 \times 10^{5}$ & $1.33 \times 10^{5}$ & $2.16 \times 10^{4}$ \\
\hline Ethyl acetoacetate & $\mathrm{EAA}_{\text {ctrl }}$ & $3.71 \times 10^{5}$ & $4.17 \times 10^{5}$ & $0.94 \times 10^{4}$ \\
& $\mathrm{EAA}_{\text {scmt }}$ & $2.96 \times 10^{5}$ & $3.53 \times 10^{5}$ & $1.53 \times 10^{4}$ \\
\hline$p$-Cresyl methyl ether & $\mathrm{PCME}_{\text {ctrl }}$ & $3.08 \times 10^{5}$ & $2.59 \times 10^{5}$ & $10.7 \times 10^{4}$ \\
& $\mathrm{PCME}_{\text {scmt }}$ & $2.96 \times 10^{5}$ & $1.50 \times 10^{5}$ & $0.84 \times 10^{4}$ \\
\hline 94085 Floral-fruity & SexG $_{\text {ctrl }}$ & $5.12 \times 10^{5}$ & $3.00 \times 10^{5}$ & $4.02 \times 10^{4}$ \\
& SexG $_{\text {scmt }}$ & $4.38 \times 10^{5}$ & $3.78 \times 10^{5}$ & $10.4 \times 10^{4}$ \\
\hline
\end{tabular}

Table 3: Fixative efficiency (\%FX $\mathrm{Fff})$ of SCM-chitosan in different perfume preparations

\begin{tabular}{lccc}
\hline & \multicolumn{3}{c}{ Fixative efficiency $\left(\boldsymbol{\%} \boldsymbol{X}_{\text {eff }}\right)$} \\
\cline { 2 - 4 } Sample code & $\mathbf{2 5}{ }^{\circ} \mathbf{C}$ & $\mathbf{3 5}^{\circ} \mathbf{C}$ & $\mathbf{5 3}^{\circ} \mathbf{C}$ \\
\hline BAL $_{\text {scmt }}$ & 24.7 & 57.9 & 38.1 \\
EAA $_{\text {scmt }}$ & 20.2 & 15.4 & -62.8 \\
PCME $_{\mathrm{scmt}}$ & 3.9 & 42.1 & 92.2 \\
SexG $_{\text {scmt }}$ & 14.5 & -26.0 & -158.7 \\
\hline
\end{tabular}

\section{DISCUSSION}

All products containing SCM-chitosan showed lower volatile content compared to the formulation without SCM-chitosan. Hydrogen bonding between SCM-chitosan and water, alcohol or perfume compound may be responsible for the reduction in volatility. The results obtained show that $p$-cresyl methyl ether with SCM-chitosan $\left(\mathrm{PCME}_{\mathrm{scmt}}\right)$ had greater fixative efficiency the higher the temperature, and was as high as $92.2 \%$ at $53{ }^{\circ} \mathrm{C}$. The fixative efficiency of SCM-chitosan on benzyl alcohol $\left(B A L_{\text {scmt }}\right)$ also increased with rise in temperature but the breakpoint occurred at some point between 35 and $53{ }^{\circ} \mathrm{C}$. Increase in volatility suppression (and hence fixation) with an increase in temperature may be partly caused by conformation change or micellization of SCMchitosan in the system $[2,10]$.

The effect of SCM-chitosan on ethyl acetoacetate $\left(E A_{s c m t}\right)$ and 94085 floral-fruity $\left(\right.$ SexG $\left.\mathrm{scmt}_{\mathrm{t}}\right)$ produced inexplicable results at some of the temperatures studied. Other than the remarkable low concentration of the active perfume compounds previously mentioned, it may be due to the precipitation of SCM-chitosan in the preparation which was observed after analysis (post-day 21). The precipitation may result in reduced SCM-chitosan in the preparation which consequently reduces hydrogen bonding between SCM-chitosan and perfume compounds. Sodium ion in SCMchitosan reacts with ethyl acetoacetate to produce ethyl acetoacetate salt. When it precipitated, the equilibrium of eau de cologne in the vial changed which indicates diminished ethyl acetoacetate in the system.

\section{CONCLUSION}

Sodium carboxymethyl chitosan (SCM-chitosan) can be used effectively as a fixative for eau de cologne products. SCM-chitosan is soluble in water but insoluble in ethanol, the two main components in eau de cologne formulations. The fixative effect of SCM-chitosan is particularly pronounced in the formulations containing $p$-cresyl methyl ether. However, systems containing benzyl alcohol, ethyl acetoacetate and 94085 floral-fruity showed precipitation after 21 days. Thus, solubility of chitosan in aqueous alcohol is the main limitation to the fixation of volatile perfume in eau de cologne preparations. Consequently, modification of chitosan to improve its solubility in the system may aid its application in the preparation of eau de cologne products.

\section{ACKNOWLEDGEMENT}

The authors gratefully acknowledge the National Research University Project under Thailand's Office of the Higher Education Commission (CHE), Thailand, for financial support and also thank Mae Fah Luang University for providing space and facilities for this work. We also thank Bangkok Perfumery, Co, Ltd for providing perfume samples used in this study.

\section{REFERENCES}

1. De Navarre MG. Chemistry and manufacturing of cosmetics. $2^{\text {nd }}$ ed. The Continental Press, Orlando, Florida, 1975.

2. Suzuki K, Saito $Y$, Tokuoka $Y$, Abe $M$, Sato $T$. Poly(ethylene oxide)/poly(propylene oxide)/poly (ethylene oxide) triblock copolymer as a sustainedrelease carrier for perfume compounds. J. Am. Oil Chem. Soc. 1997; 74(1): 55-59.

3. Numanoglu $U$, Sen $T$, fer Tarimci $N$, Kartal M, Koo OMY, Önyüksel $H$. Use of cyclodextrins as a cosmetic delivery system for fragrance materials: linalool and benzyl acetate. AAPS Pharm. Cni Tech. 2007; 8: E1-E9. 
4. Hong K, Park S. Preparation of polyurethane microcapsules with different soft segments and their characteristics. React. Funct. Polym. 1999; 42: 193-200.

5. Curtis T, Williams DG. An introduction to perfumery. $2^{\text {nd }}$ ed. Micelle Press, New York, 2001.

6. Hsieh $W-C$, Chang $C-P$, Gao $Y-L$. Controlled release properties of chitosan encapsulated volatile citronella oil microcapsules by thermal treatments. Colloid Surface B. 2006; 53: 209-214.

7. Pillai CKS, Paul W, Sharma CP. Chitin and chitosan polymers: chemistry, solubility and fiber formation. Prog. Polym. Sci. 2009; 34: 642-678.
8. Jayakumar $R$, Prabaharan $M$, Nair SV, Tokura $S$, Tamura $H$, Selvamurugan N. Novel carboxymethyl derivatives of chitin and chitosan materials and their biomedical applications. Prog. Mater. Sci. 2010; 55: 675-709.

9. Liu XF, Guan YL, Yang DZ, Li Z, Yao KD. Antibacterial action of chitosan and carboxymethylated chitosan. J. Appl. Polym. Sci. 2001; 79(7): 1324-1335.

10. Zhang C, Ding Y, Ping Q, (Lucy) Lu L. Novel chitosanderived nanomaterials and their micelle-forming properties. J. Agric. Food Chem. 2006; 54: 84098416. 